\title{
Spatially resolved analysis of plutonium isotopic signatures in environmental particle samples by laser ablation-MC-ICP-MS
}

\author{
Stefanie Konegger-Kappel ${ }^{1,2}$ - Thomas Prohaska ${ }^{1}$
}

Received: 13 May 2015 /Revised: 21 June 2015 / Accepted: 22 June 2015 /Published online: 14 July 2015

(C) The Author(s) 2015. This article is published with open access at Springerlink.com

\begin{abstract}
Laser ablation-multi-collector-inductively coupled plasma mass spectrometry (LA-MC-ICP-MS) was optimized and investigated with respect to its performance for determining spatially resolved $\mathrm{Pu}$ isotopic signatures within radioactive fuel particle clusters. Fuel particles had been emitted from the Chernobyl nuclear power plant (ChNPP) where the 1986 accident occurred and were deposited in the surrounding soil, where weathering processes caused their transformation into radioactive clusters, so-called micro-samples. The size of the investigated micro-samples, which showed surface alpha activities below $40 \mathrm{mBq}$, ranged from about 200 to $1000 \mu \mathrm{m}$. Direct single static point ablations allowed to identify variations of $\mathrm{Pu}$ isotopic signatures not only between distinct fuel particle clusters but also within individual clusters. The resolution was limited to 100 to $120 \mu \mathrm{m}$ as a result of the applied laser ablation spot sizes and the resolving power of the nuclear track radiography methodology that was applied for particle pre-selection. The determined ${ }^{242} \mathrm{Pu} /{ }^{239} \mathrm{Pu}$ and ${ }^{240} \mathrm{Pu} /{ }^{239} \mathrm{Pu}$ isotope ratios showed a variation from low to high $\mathrm{Pu}$ isotope ratios, ranging from $0.007(2)$ to $0.047(8)$ for ${ }^{242} \mathrm{Pu} /{ }^{239} \mathrm{Pu}$ and
\end{abstract}

Published in the topical collection Applications of Isotopes in Analytical Ecogeochemistry with guest editors Thomas Prohaska, Andreas Zitek, and Johanna Irrgeher.

Stefanie Konegger-Kappel

s.konegger-kappel@iaea.org

1 Department of Chemistry, Division of Analytical Chemistry, Research Group Analytical Ecogeochemistry, University of Natural Resources and Life Sciences, Vienna, Konrad-Lorenz-Straße 24, 3430 Tulln, Austria

2 Present address: Office of Safeguards Analytical Services, Department of Safeguards, International Atomic Energy Agency (IAEA), Vienna International Centre, PO Box 100, 1400 Vienna, Austria from $0.183(13)$ to $0.577(40)$ for ${ }^{240} \mathrm{Pu} /{ }^{239} \mathrm{Pu}$. In contrast to other studies, the applied methodology allowed for the first time to display the $\mathrm{Pu}$ isotopic distribution in the Chernobyl fallout, which reflects the differences in the spent fuel composition over the reactor core. The measured $\mathrm{Pu}$ isotopic signatures are in good agreement with the expected $\mathrm{Pu}$ isotopic composition distribution that is typical for a RBMK-1000 reactor, indicating that the analyzed samples are originating from the ill-fated Chernobyl reactor. The average $\mathrm{Pu}$ isotope ratios $\left[{ }^{240} \mathrm{Pu} /{ }^{239} \mathrm{Pu}=0.388(86),{ }^{242} \mathrm{Pu} /{ }^{239} \mathrm{Pu}=0.028(11)\right]$ that were calculated from all investigated samples $(n=48)$ correspond well to previously published results of $\mathrm{Pu}$ analyses in contaminated samples from the vicinity of the Chernobyl NPP [e.g. ${ }^{240} \mathrm{Pu} /{ }^{239} \mathrm{Pu}=0.394(2)$ and ${ }^{242} \mathrm{Pu} /{ }^{239} \mathrm{Pu}=$ 0.027(1); Nunnemann et al. (J Alloys Compd 271273:45-48, 1998)].

Keywords Plutonium isotope ratios · Environmental contamination $\cdot$ Chernobyl nuclear power plant .

(MC)-ICP-MS · Laser ablation

\section{Introduction}

Monitoring of environmental contaminations with actinides is of special interest not only for the assessment of human hazards $[1,2]$ and timely radiation protection measures but also for gaining information about radiological impacts on flora and fauna [3]. Moreover, the knowledge of chemical and isotopic compositions of nuclear material, reflecting the origin, intended use and ongoing nuclear activities, is of particular importance for nuclear forensics [4] and nuclear safeguards [5].

Nowadays, radionuclides are mainly released into the environment due to nuclear fuel cycle operations, including 
releases from reprocessing plants or waste deposits and due to nuclear accidents [6-10]. However, in the twentieth century, large amounts of $\mathrm{Pu}$ were released into the environment as a consequence of stratospheric nuclear weapon tests that took place between 1945 and 1975, with a maximum emission around $1963[11,12]$. The Pu isotopic signatures of this global fallout are well known today due to the establishment of regional $\mathrm{Pu}$ isotopic baselines [13], which helps to recognize additional $\mathrm{Pu}$ inputs into the ecosystem. The mean ${ }^{239} \mathrm{Pu}$ concentration for surface soil is about $10^{-13} \mathrm{~g} \mathrm{~g}^{-1}$. Pu concentrations larger than $10^{-12} \mathrm{~g} \mathrm{~g}^{-1}$ are regarded as hazardous when accumulated in the human body [2].

About $1-2 \%$ of the global Pu content present in the environment back in the 1980s [2] was emitted during the accident at the fourth unit of the Chernobyl nuclear power plant (ChNPP-4) on the 26th of April 1986. Pu was mainly released in form of fuel particles as it was associated with the uranium fuel that was emitted from the reactor core. It got deposited in the surrounding soil, mainly contaminating the $30-\mathrm{km}$ zone around the accidental reactor $[14,15]$. The deposited fuel particles varied, according to the scenarios during the accident, in their chemical compositions, morphologies and oxidation states [16]. The fate of fuel particles in the environment depends on both their chemical properties and environmental conditions [15]. Non-oxidized particles are regarded as relatively chemically stable, whereas the oxidized fraction is more susceptible to weathering [17] and dissolution in soil, which promotes the mobilization of radionuclides into the ecosystem [15]. Oxidation and weathering processes can furthermore lead to superficial cracking of particle surfaces and their transformation into radioactive clusters - so-called micro-samples - with sizes of up to several hundreds of micrometers [18].

A very well-established technique for analyzing $\mathrm{Pu}$ isotopes and other alpha-emitting radionuclides with half-lives less than 1000 years is alpha-spectrometry [19-21]. However, in the case of low activities and concentrations, as is mostly the case for environmental samples, measurement times of several days or even weeks might be required for gaining reliable analytical results. Moreover, only a sum activity of ${ }^{239} \mathrm{Pu}$ and ${ }^{240} \mathrm{Pu}$ can be obtained due to the similar alpha energies of these two isotopes $\left(5.16 \mathrm{MeV}\right.$ for ${ }^{239} \mathrm{Pu}$ and $5.17 \mathrm{MeV}$ for ${ }^{240} \mathrm{Pu}$ ). Complimentary methods for Pu isotopic analysis can be found in the field of mass spectrometry (i.e. inductively coupled plasma mass spectrometry (ICP-MS) [12, 22], thermal ionization mass spectrometry (TIMS) [23], resonance ionization mass spectrometry (RIMS) [24, 25] and accelerator mass spectrometry (AMS) $[19,21]$ ), which relevance is also highlighted by numerous reviews [12, 22, 26-30] dedicated to this topic. Especially analyses performed by ICP-MS are offering easy sample preparation, relatively low analysis costs and high sample throughput due to short analysis times, with all being merits for environmental sample analyses. In the last years, the combination of ICP-MS with laser ablation for direct solid sampling has also more and more found its way into the field of nuclear safeguards and nuclear forensics (e.g. [31-33]). While laser ablation allows to resolve a sample's inherent isotopic and elemental information as well as within-sample inhomogeneities, ICP-MS offers high sensitivity for the analysis of very low actinide amounts [30, 34]. Because of this and its comparatively low susceptibility for molecular clusters at actinide mass-to-charge ratios, laser ablation (LA)-ICP-MS is regarded as an attractive complementary method to well-established mass spectrometric techniques (i.e. fission track-TIMS [35] and secondary ion mass spectrometry (SIMS)) for actinide particle analyses [32]. The attractiveness of LA-ICP-MS does not at last result from the circumstance that one could proceed very quickly from sample to sample in emergency situations, allowing a fast assessment of environmental contaminations and their origins. However, as LA-ICP-MS is a comparatively new method in this field, an expanded knowledge about its performance is required for further evaluating its applicability for various particle sample matrices. In a previous study that was published by Boulyga and Prohaska [18], the potential of LA-ICP-MS was demonstrated for the spatially resolved analysis of $\mathrm{U}, \mathrm{Nd}$ and $\mathrm{Ru} /(\mathrm{Ru}+\mathrm{Tc})$ isotope ratios in Chernobyl micro-samples.

The aim of this study was the adaptation and optimization of the LA-multi-collector (MC)-ICP-MS methodology for spatially resolved $\mathrm{Pu}$ isotope ratio measurements in radioactive fuel particle cluster samples that were collected in the same batch as those analyzed in the previous study [18]. A modified multi-collector set-up allowed to measure ultra-trace $\mathrm{Pu}$ isotope amounts, whereas the use of laser ablation sampling allowed to determining variations of the $\mathrm{Pu}$ isotopic composition both between and within individual fuel particle cluster samples. Up to now, only a very limited amount of data has been available for individual hot particle samples from the Chernobyl fallout [36, 37]. Since, in this study, a large number of individual particle cluster samples $(n=48)$ were analyzed and spatially resolved for the $\mathrm{Pu}$ isotopic composition, important insights are provided for the first time about the distribution of the spent fuel composition over the reactor core at the time of the accident.

\section{Experimental}

Samples and sample preparation Micro-samples (i.e. radioactive fuel particle clusters embedded in a soil matrix) emitted during the Chernobyl accident were sampled in the vicinity of the Chernobyl nuclear power plant (Ch-NPP) $(8 \mathrm{~km}$ to the north-west of the Ch-NPP) in 1992. The soil samples were taken in an area that has remained anthropogenically untouched since the accident. Sampling, sample preparation as well as nuclear track radiography analyses for particle identification and localization were performed at the Institute of 
Power Engineering, Minsk, Belarus, in 1992. Experimental details are given elsewhere [18]. The identified micro-samples, which were measured by nuclear track radiography, yielded sizes and surface alpha activities from about 200 to $1000 \mu \mathrm{m}$ and from 3 to $38 \mathrm{mBq}$, respectively. The microsamples were embedded in cellulose acetate membrane filters (OE 67, Whatman; GE Healthcare, UK). Exposure to acetone vapour resulted in transparent membranes, which were affixed to circular glass plates $(d=25 \mathrm{~mm})$ by means of commercially available glue [38]. The glass plates were directly put into the laser ablation cell.

Reagents and certified reference material The analyses of the Chernobyl micro-samples included measurements of $1 \%$ $(\mathrm{m} / \mathrm{m})$ nitric acid $\left(\mathrm{HNO}_{3}\right)$ as blank solution and CRM U500 (New Brunswick Laboratory, U.S. Department of Energy, USA), a U solution isotopic reference material, for instrument optimization and the determination of external correction factors for correcting mass bias and secondary electron multiplier gain. Sixty-five percent $(\mathrm{m} / \mathrm{m}) \mathrm{HNO}_{3}$ (analytical reagent grade; Merck KGaA, Darmstadt, Germany) was diluted with reagent grade type I water $\left(18.2 \mathrm{M} \Omega / \mathrm{cm}\right.$ at $25^{\circ} \mathrm{C}$, Ultra Clear Basic Reinstwassersystem; SG Wasseraufbereitung und Regenerierstation GmbH, Barsbüttel, Germany). Both were purified by sub-boiling distillation (Milestone-MLS GmbH, Leutkirch, Germany) prior to use.

LA-MC-ICP-MS instrumentation Pu isotope ratio measurements were accomplished with a double-focusing high-resolution sector field MC-ICP-MS (Nu Plasma HR; Nu Instruments Limited, Wrexham, UK) that was coupled to a solidstate nanosecond LA system (UP193 Solid State Laser Ablation System (Nd:YAG); ESI-NWR Division, Electro Scientific Industries, Inc., Portland, CA, USA) for direct solid sample introduction. A membrane desolvation system (DSN-100; $\mathrm{Nu}$ Instruments Limited, Wrexham, UK) was connected in parallel to the laser ablation system for measuring a U solution isotopic reference material (CRM U500) for determining external correction factors (mass bias and secondary electron multiplier gain) in between the analyses of the solid microsamples according to a standard-sample bracketing approach. The desolvation unit allowed introducing a dry aerosol into the ICP, thus reducing interferences by molecular ions, such as oxides and hydrides $[14,28]$. No solution was aspirated during laser ablation.

Based on the results of a previous study [18], the standard collector block of the multi-collector was modified for simultaneously measuring ultra-trace ${ }^{239} \mathrm{Pu}^{+},{ }^{240} \mathrm{Pu}^{+}$and ${ }^{242} \mathrm{Pu}^{+}$isotope amounts with three secondary electron multipliers (SEMs) (see Fig. 1). A deflection lens deflected the ion beam into the low mass side SEM for measuring the above-mentioned isotopes (see "Results and discussion" section for more details). Instrumental parameters are summarized in Table 1.
Data Processing The measured ${ }^{239} \mathrm{Pu}^{+},{ }^{240} \mathrm{Pu}^{+}$and ${ }^{242} \mathrm{Pu}^{+}$ signal intensities were recorded in time-resolved analysis mode with an acquisition time of $1 \mathrm{~s}$ per data point. A typical laser ablation analysis performing static point ablation lasted for about 20-40 s, excluding the time for measuring Ar gas blanks. Ar gas blanks were recorded for about $10 \mathrm{~s}$ prior to the start of the ablation of the micro-samples in order to guarantee a complete wash-out of the previous ablation. The maximum recorded signal intensities per ablation ranged from about 160-600,000 counts per second (cps) for ${ }^{239} \mathrm{Pu}, 60-284$, $000 \mathrm{cps}$ for ${ }^{240} \mathrm{Pu}$ and $7-19,000 \mathrm{cps}$ for ${ }^{242} \mathrm{Pu}$. Dead time correction of the measured intensities was automatically performed in the Nu Plasma software, applying dead times of 8.5, 10 and $11 \mathrm{~ns}$ for SEMs IC0, IC1 and IC2, respectively.

Calculation of the ${ }^{242} \mathrm{Pu} /{ }^{239} \mathrm{Pu}$ and ${ }^{240} \mathrm{Pu} /{ }^{239} \mathrm{Pu}$ isotope ratios was performed with the help of the slope of scatter plot regression lines [33, 39]. The main advantage of this data processing strategy is that each data point, including the blank, is taken into account and that the contribution of each data point to the linear fit depends on its signal intensity. Thus, higher signal intensities, usually yielding more precise data than lower signal intensities, are dominating the fit, which is regarded to be advantageous, especially when processing time-resolved ablation profiles [33]. The ${ }^{242} \mathrm{Pu} /{ }^{239} \mathrm{Pu}$ and ${ }^{240} \mathrm{Pu} /{ }^{239} \mathrm{Pu}$ isotope ratios were corrected for mass bias and secondary electron multiplier gain. The external correction factors were derived by measuring ${ }^{238} \mathrm{U} /{ }^{235} \mathrm{U}$ and ${ }^{236} \mathrm{U} /{ }^{235} \mathrm{U}$ isotope ratios in CRM U500 for at least $10 \mathrm{~min}$ in a bracketing approach, assuming similar mass bias effects of $\mathrm{U}$ and $\mathrm{Pu}$ [i.e. $\mathrm{f}\left({ }^{236} \mathrm{U} /{ }^{235} \mathrm{U}\right)=\mathrm{f}\left({ }^{240} \mathrm{Pu} /{ }^{239} \mathrm{Pu}\right)$ and $\mathrm{f}\left({ }^{238} \mathrm{U} /{ }^{235} \mathrm{U}\right)=\mathrm{f}\left({ }^{242} \mathrm{Pu} /{ }^{239}\right.$ $\mathrm{Pu})$ ]. ${ }^{238} \mathrm{U}$ and ${ }^{242} \mathrm{Pu}$ were measured with IC0, ${ }^{236} \mathrm{U}$ and ${ }^{240} \mathrm{Pu}$ with IC1, and ${ }^{235} \mathrm{U}$ and ${ }^{239} \mathrm{Pu}$ with IC2. The external correction factors for correcting the ${ }^{240} \mathrm{Pu} /{ }^{239} \mathrm{Pu}$ and ${ }^{242} \mathrm{Pu} /{ }^{239} \mathrm{Pu}$ isotope ratios were calculated by dividing the certified ${ }^{238} \mathrm{U} /{ }^{235} \mathrm{U}$ and ${ }^{236} \mathrm{U} /{ }^{235} \mathrm{U}$ isotope ratios with the $\mathrm{U}$ isotope ratios measured in CRM U500. ${ }^{238} \mathrm{U}$ was measured with IC0, whereas ${ }^{236} \mathrm{U}$ and ${ }^{235} \mathrm{U}$ were determined with IC1 and IC2, respectively. One percent $(m / m) \mathrm{HNO}_{3}$ was analyzed for blank correction. Both blank and CRM U500 signal intensities of the isotopes of interest were assessed by calculating an average of six blocks, with each block representing an average of 100 data points.

In the case of homogenous isotope ratio distributions within one micro-sample, ${ }^{242} \mathrm{Pu} /{ }^{239} \mathrm{Pu}$ and ${ }^{240} \mathrm{Pu} /{ }^{239} \mathrm{Pu}$ isotope ratios of more than two single static point ablations (on one micro-sample) were pooled together by calculating the weighted mean of replicate LA measurements. Weighting factors were derived from the theoretical precision of the measured signal intensities.

Uncertainty assessment Computation of expanded $(k=2)$ measurement uncertainties $(U)$ was accomplished with the GUM Workbench Pro software (version 2.4; Metrodata 


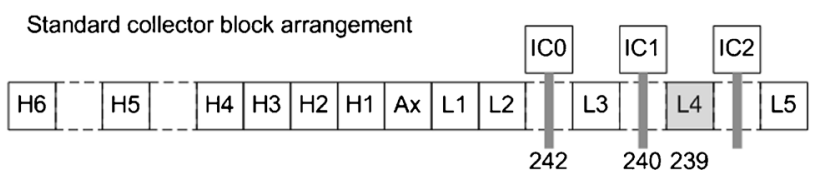

Modified collector block arrangement

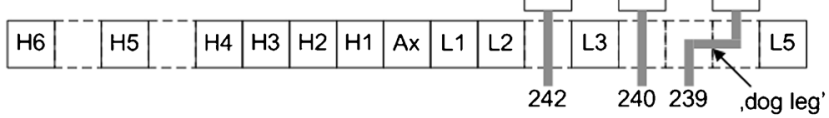
deflector

Fig. 1 Collector block arrangements of the Nu Plasma HR MC-ICP-MS ( $H$ Faraday cup high mass side, $A x$ Faraday cup axial mass, $L$ Faraday cup low mass side, $I C$ secondary electron multiplier)

GmbH, Weil am Rhein, Germany) according to ISO/GUM [40] and Eurachem [41] guidelines. Single parameters that were propagated for the expanded combined standard measurement uncertainties included blanks $\left(1 \%(\mathrm{~m} / \mathrm{m}) \mathrm{HNO}_{3}\right.$ for liquid and dark noise for LA measurements), dead times,
SEM gains, measurement repeatabilities, uncertainties of the certified ${ }^{238} \mathrm{U} /{ }^{235} \mathrm{U}$ and ${ }^{236} \mathrm{U} /{ }^{235} \mathrm{U}$ isotope ratios measured in CRM U500, ${ }^{238} \mathrm{U}^{+}$peak tailing at the mass $m-2 u$ and contributions from ${ }^{235} \mathrm{U}^{1} \mathrm{H}$ hydride ions at $m=236 u$ (CRM U500 measurements only) and ${ }^{238} \mathrm{U}^{+}$peak tailing at $m+1 u, m+2 u$ and $m+4 u$ (Pu isotope ratio measurements only). The withinmeasurement repeatability of laser ablation analyses was calculated from the uncertainty of linear regression slopes, whereas the within-measurement repeatability of liquid measurements was calculated from the standard deviation of six measurement blocks.

The ${ }^{238} \mathrm{U}^{+}$peak tailing at $m-2 u$ did not significantly contribute to the expanded combined standard measurement uncertainties of the CRM U500 measurements. This can be explained by the fact that peak tailing is less pronounced for larger ratios as is the case in this study for ${ }^{236} \mathrm{U} /{ }^{235} \mathrm{U}$ (i.e. $0.0015192(31))$. Since the ${ }^{242} \mathrm{Pu} /{ }^{239} \mathrm{Pu}$ and ${ }^{240} \mathrm{Pu} /{ }^{239} \mathrm{Pu}$ isotope ratios of the Chernobyl samples were in the same order
Table 1 LA-MC-ICP-MS instrumental parameters

\begin{tabular}{|c|c|}
\hline \multicolumn{2}{|l|}{ Laser (New wave 'UP 193’) } \\
\hline Ablation mode & Static point ablation \\
\hline Wavelength, nm & 193 \\
\hline Pulse length, ns & 3 \\
\hline Energy density, $\mathrm{J} \mathrm{cm}^{-2}$ & $1.70-5.83$ \\
\hline Power density, $\mathrm{GW} \mathrm{cm}^{-2}$ & $0.66-2.06$ \\
\hline Repetition rate, $\mathrm{Hz}$ & 10 \\
\hline Spot size, $\mu \mathrm{m}$ & $100-120$ \\
\hline Ar carrier gas flow rate, $\mathrm{L} \min ^{-1}$ & 0.7 \\
\hline \multicolumn{2}{|l|}{ Liquid sample introduction } \\
\hline System type & DSN-100 \\
\hline Nebulizer & PFA 100 \\
\hline Sample uptake rate, $\mu \mathrm{L} \min ^{-1}$ & 130 \\
\hline Nebulizer gas pressure, $\mathrm{Pa}$ & $\sim 2 \times 10^{5}$ \\
\hline Hot gas flow rate, $\mathrm{L} \min ^{-1}$ & $\sim 0.25$ \\
\hline Membrane gas flow rate, $\mathrm{L} \min ^{-1}$ & $\sim 1.4$ \\
\hline Spray chamber temperature, ${ }^{\circ} \mathrm{C}$ & $112-116$ \\
\hline Membrane temperature, ${ }^{\circ} \mathrm{C}$ & $119-123$ \\
\hline \multicolumn{2}{|l|}{ MC-ICP-MS (Nu Plasma HR) } \\
\hline RF power, $\mathrm{W}$ & 1300 \\
\hline Auxiliary gas flow rate, $\mathrm{L} \mathrm{min}^{-1}$ & 0.95 \\
\hline Cool gas flow rate, $\mathrm{L} \mathrm{min}^{-1}$ & 13 \\
\hline Mass separation & 1 \\
\hline Isotopes monitored & ${ }^{235} \mathrm{U},{ }^{236} \mathrm{U},{ }^{238} \mathrm{U},{ }^{239} \mathrm{Pu},{ }^{240} \mathrm{Pu},{ }^{242} \mathrm{Pu}$ \\
\hline Resolution, $\mathrm{m} / \Delta \mathrm{m}$ & 300 (low resolution) \\
\hline Detection system & $\mathrm{IC} 0^{\mathrm{a}}, \mathrm{IC}^{\mathrm{a}}, \mathrm{IC} 2^{\mathrm{a}}$ \\
\hline High voltages, source and transfer lens parameters & Optimized for optimal sensitivity \\
\hline Voltages applied to collector and multipliers & Optimized for optimal peak shape and alignment \\
\hline Data acquisition mode & TRA (acquisition time per data point $=1 \mathrm{~s}$ ) \\
\hline
\end{tabular}

TRA time-resolved analysis

${ }^{\text {a }}$ Secondary electron multiplier 
of magnitude or larger, peak tailing of ${ }^{239} \mathrm{Pu}$ into the masses of

${ }^{240} \mathrm{Pu}$ and ${ }^{242} \mathrm{Pu}$ was neglected in the uncertainty propagation

of the results of the micro-sample measurements.

Peak tailing effects of ${ }^{238} \mathrm{U}^{+}$ions, originating from $U$ present in the analyzed micro-sample cluster, on the masses of the $\mathrm{Pu}$ isotopes at $m+1 u, m+2 u$ and $m+4 u$ were assessed by measuring U500 at an axial mass of $m=245 u$. This procedure allowed assessing the peak tailing of ${ }^{238} \mathrm{U}^{+}$ions at the masses of $m+1 u, m+2 u$ and $m+4 u$. The relative intensities at the masses $m=242 u, m=240 u$ and $m=239 u$ that were normalized to the intensity of ${ }^{238} \mathrm{U}^{+}$ions were about $4 \times 10^{-7}, 3 \times 10^{-6}$ and $3 \times 10^{-5}$. The relative intensities at the masses of $m=242 u$ and $m=240 u$ are reflecting the peak tailing from ${ }^{238} \mathrm{U}^{+}$ions, whereas the relative intensities at the mass $m+1 u$ are representing both peak tailing and a contribution from ${ }^{238} \mathrm{U}^{1} \mathrm{H}^{+}$hydride ions.

\section{Results and discussion}

\section{Spatially resolved Pu isotopic analysis of environmental particle samples}

Micro-sample pre-selection Generally, the size of the laser beam can be a major limitation for single particle analysis, especially for particles with sizes in the low or submicrometer range [33]. Hence, particle pre-identification, selection and separation from their matrix or from neighbouring particles are considered beneficial for decreasing the risk of simultaneously ablating neighbouring particles and obtaining mixed isotopic information [31]. In the case of the particle samples analyzed in this study, the identification and preselection of particles of interest from the collected soil was particularly deemed necessary for increasing the LA sample throughput.

Theoretically, pre-selection of particles or areas of interest could be accomplished by performing a fast pre-ablation of the sample surface. However, due to limited sample material, the applicability of such a pre-ablation is limited for particle samples as well as for samples containing ultra-trace actinide amounts as was the case in this study, where individual microsamples contained $\mathrm{Pu}$ amounts in the picogram to femtogram range. In the case of the Chernobyl micro-samples, relatively large spot sizes $(100-120 \mu \mathrm{m})$ and laser repetition rates $(10 \mathrm{~Hz})$ were required for obtaining a good, measurable signal for improving accuracy and precision. In the case of a preablation that yielded useful data for pre-selection, not enough sample material would have been left for the actual isotope ratio analysis. Therefore, combining a pre-selection method like nuclear track radiography and LA-MC-ICP-MS for environmental particle analysis, as performed in this study, has been regarded as beneficial for decreasing the LA-ICP-MS analysis time and thus increasing sample throughput. As a result of the applied laser ablation spot sizes and the resolving power of nuclear track radiography, the resolution for identifying individual particles was limited to $100-120 \mu \mathrm{m}$ in this study.

MC-ICP-MS collector block modification In contrast to other studies (e.g. [42-44]), where ultra-trace concentration levels of $\mathrm{Pu}$ isotopes in environmental samples had been determined by applying a single collector ICP-MS, a multicollector-ICP-MS instrument was applied here, especially following the need that the isotope ratio has to be determined on short transient signals to not compromise measurement precision and accuracy of $\mathrm{Pu}$ isotope ratio measurements. Similar to a previous study on $\mathrm{U}, \mathrm{Nd}$ and $\mathrm{Ru} /(\mathrm{Ru}+\mathrm{Tc})$ isotope ratios [18], the standard collector block of the Nu Plasma HR multicollector was modified for measuring ${ }^{239} \mathrm{Pu}^{+},{ }^{240} \mathrm{Pu}^{+}$and ${ }^{242} \mathrm{Pu}^{+}$simultaneously with three SEMs (Fig. 1). The standard collector block arrangement was modified using a so-called 'dog leg' deflector lens that was inserted at the L4 Faraday cup position and allowed to guide the ${ }^{239} \mathrm{Pu}^{+}$ion beam from the $\mathrm{L} 4$ position into IC2. This set-up was different from the previous study [18], where the ion pathway was redirected at the high mass side for measuring all isotopes with SEMs. The modification that is shown in Fig. 1 was deemed necessary for overcoming the lack of sensitivity of Faraday cups for measuring the very low $\mathrm{Pu}$ amounts (pg to fg amounts) present in the Chernobyl micro-samples.

\section{Pu isotopic signatures determined in the Chernobyl fallout}

The micro-samples (Fig. 2) investigated in this study were regarded as ideal test material for extending the understanding about the performance of LA-MC-ICP-MS for spatially resolving radionuclide isotopic signatures in environmental particle samples as they exhibited low surface alpha activities (3$38 \mathrm{mBq}$ ) and ultra-trace Pu amount levels (pg to fg). Since the particles were emitted during the explosion of the accidental RBMK-1000 Chernobyl reactor, which typical characteristic was fuel replacement during operation, varying isotopic distributions of the micro-samples were presumed. Another advantage of these fuel particle cluster samples was the presence of isotopic heterogeneities within micro-samples, probably due to the generation of particle agglomerates during the explosion or of clusters due to weathering processes after their deposition [18]. This characteristic as well as the sizes of these cluster samples $(200-1000 \mu \mathrm{m})$ allowed to investigate the resolving limits of the hereproposed analytical method.

Homogeneous Pu isotopic compositions Individual microsamples were considered to be homogeneous if several static point ablations $(n \geq 2$, spot size $=100 \mu \mathrm{m})$ on the same microsample yielded no significant differences for their $\mathrm{Pu}$ isotope 


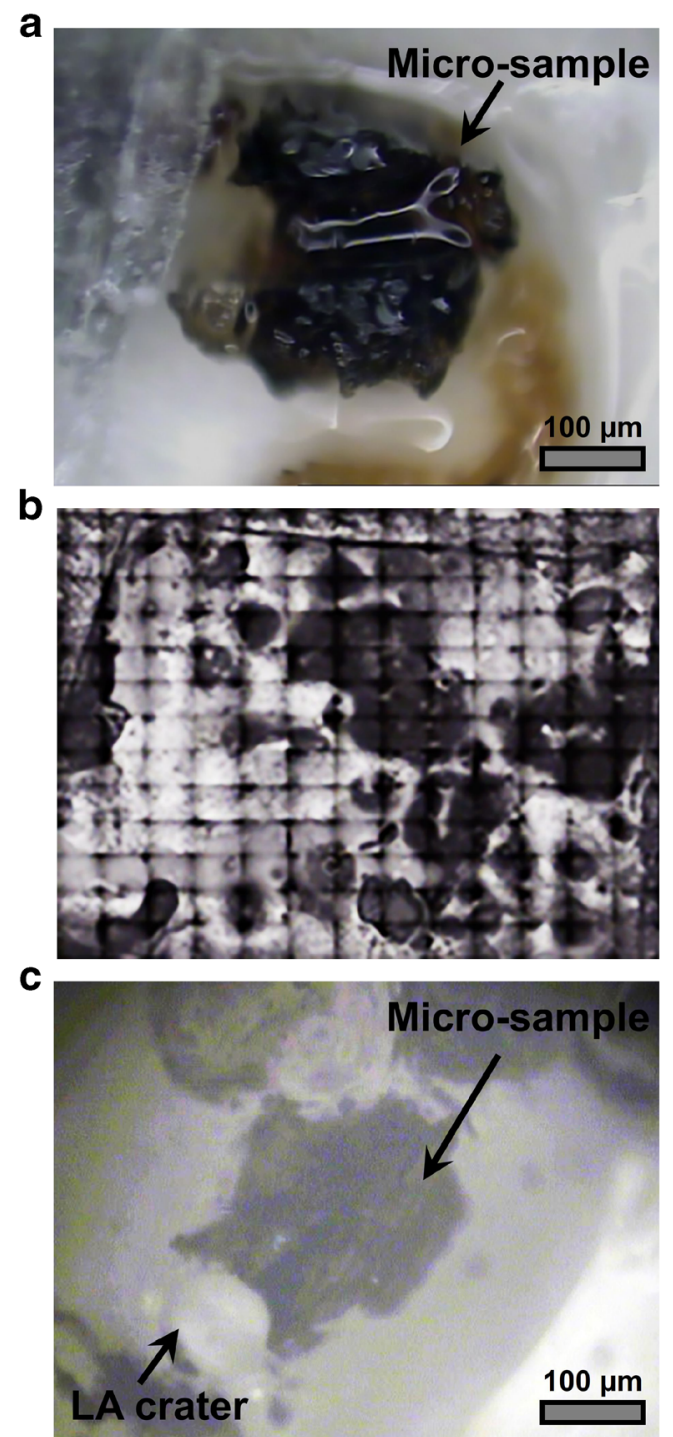

Fig. 2 Depiction of micro-samples (radioactive fuel particle clusters) that were collected in the vicinity of the accidental Chernobyl reactor: (A) typical micro-sample embedded in a transparent membrane after preselection by nuclear track radiography, (B) LA sample map overview of a transparent membrane $\left(\sim 507 \mathrm{~mm}^{2}\right)$ containing several micro-samples (dark spots) and (C) typical micro-sample after performing one static point ablation

ratios on a $95 \%$ confidence interval $(k=2)$. In Fig. 3, the $\mathrm{Pu}$ isotopic compositions that were determined for micro-samples, which showed within-sample homogeneity but between-sample heterogeneity, are depicted. An estimate of the sizes of the micro-samples can be derived from the respective ablation areas, which ranged from approximately 0.023 $0.034 \mathrm{~mm}^{2}$ for smaller clusters (Fig. 3A) and from 0.045 to $0.147 \mathrm{~mm}^{2}$ for larger ones (Fig. 3B).

The isotopic compositions were calculated as weighted means of ${ }^{242} \mathrm{Pu} /{ }^{239} \mathrm{Pu}$ and ${ }^{240} \mathrm{Pu} /{ }^{239} \mathrm{Pu}$, respectively, isotope ratios determined per micro-sample if the isotope ratios did not yield a significant difference within the expanded $(k=2)$ measurement uncertainties. The expanded uncertainties $(k=2)$
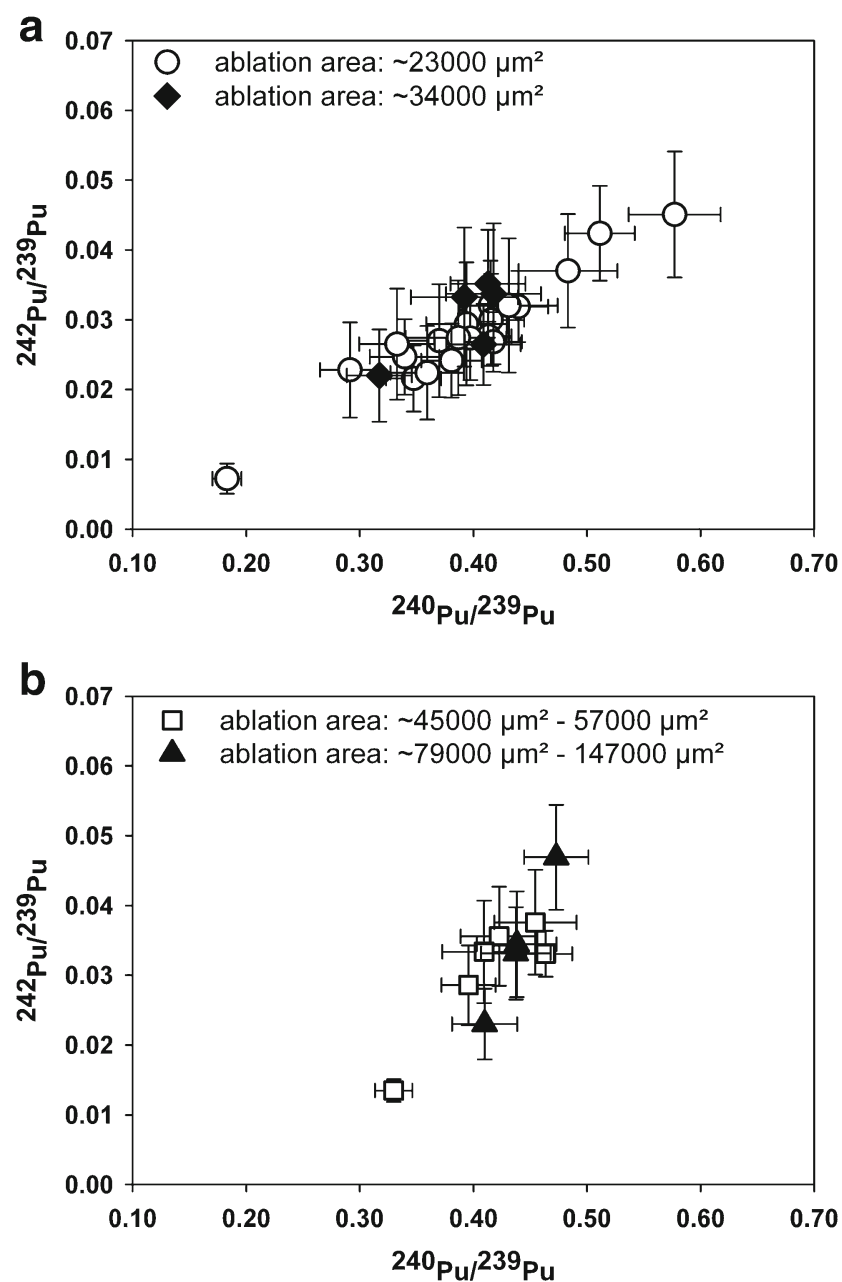

Fig. $3 \mathrm{Pu}$ isotopic compositions of micro-samples $(n=35)$ collected in the vicinity of the accidental ChNPP-4. ${ }^{242} \mathrm{Pu} /{ }^{239} \mathrm{Pu}$ and ${ }^{240} \mathrm{Pu} /{ }^{239} \mathrm{Pu}$ isotope ratios were calculated as weighted means of isotope ratios measured per micro-sample. The distribution of the $\mathrm{Pu}$ isotopic compositions is shown for smaller (A) and larger (B) micro-samples (sizes are expressed as ablation areas). Expanded $(k=2)$ measurement uncertainties $(U)$ are displayed in form of error bars

for individual spot ablations ranged from 4 to $46 \%$ for ${ }^{242} \mathrm{Pu} /{ }^{239} \mathrm{Pu}$ and from 5 to $12 \%$ for ${ }^{240} \mathrm{Pu} /{ }^{239} \mathrm{Pu}$ isotope ratios. Repeatability of LA measurements and the ${ }^{240} \mathrm{Pu}$ blank were identified as main contributors (Fig. 4A) to the uncertainty for ${ }^{240} \mathrm{Pu} /{ }^{239} \mathrm{Pu}$ isotope ratio measurements. Other contributing parameters were SEM gain variations (both LA and liquid CRM measurements) and the dead time in case of the CRM measurement of the major isotope $\left({ }^{235} \mathrm{U}\right)$. In case of ${ }^{242} \mathrm{Pu} /{ }^{239-}$ $\mathrm{Pu}$ isotope ratio measurements (see Fig. 4B), repeatability of the LA measurements and ${ }^{242} \mathrm{Pu}$ blank were identified as main contributors, whereas blank contribution became less pronounced with ${ }^{242} \mathrm{Pu}$ count rates higher than $100 \mathrm{cps}$. The within-LA measurement repeatabilities (internal precisions) for individual spot ablations ranged from 0.6 to $34.0 \%$ and from 0.2 to $5.1 \%$ for ${ }^{242} \mathrm{Pu} /{ }^{239} \mathrm{Pu}$ and ${ }^{240} \mathrm{Pu} /{ }^{239} \mathrm{Pu}$, respectively. In comparison, external precisions (calculated as relative 

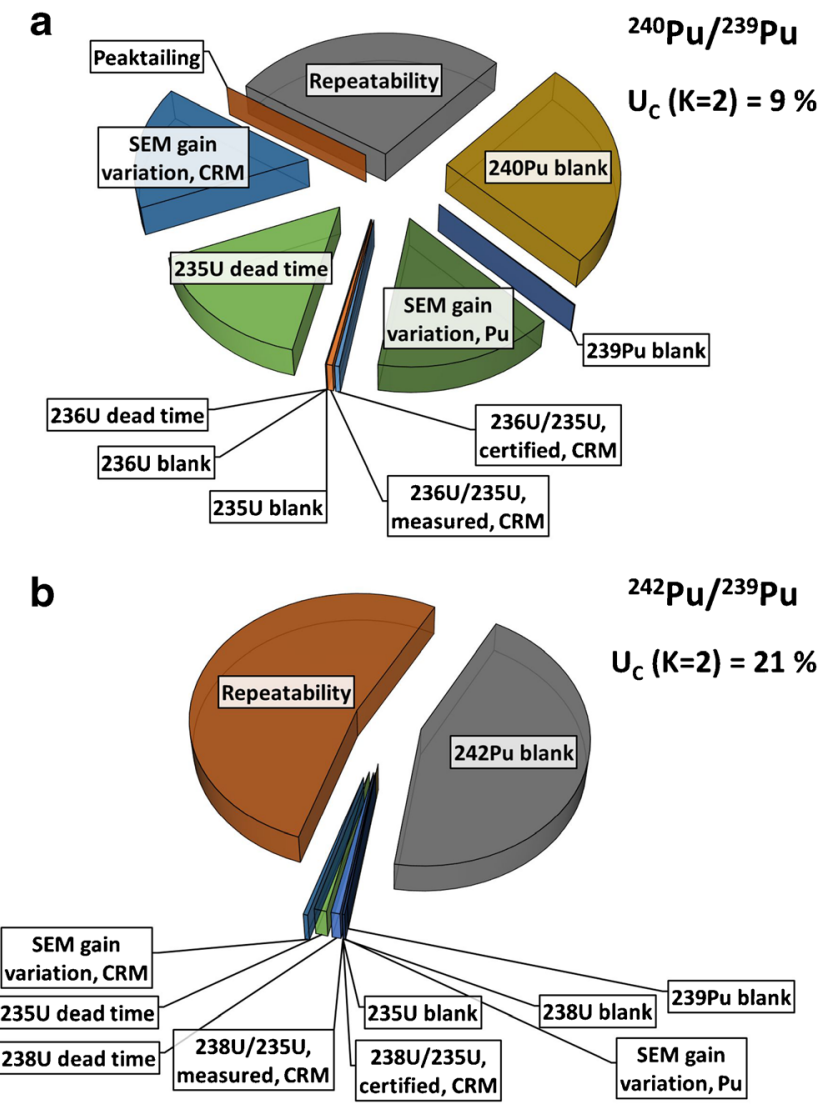

Fig. 4 Parameters contributing to the expanded measurement uncertainties $(U)(k=2)$ of $(\mathbf{A}){ }^{240} \mathrm{Pu} /{ }^{239} \mathrm{Pu}$ and $(\mathbf{B}){ }^{242} \mathrm{Pu} /{ }^{239} \mathrm{Pu}$

standard deviation of individual spot ablations per homogenous micro-sample) ranged from 0.3 to $37.1 \%$ for ${ }^{242} \mathrm{Pu} /{ }^{239} \mathrm{Pu}$ and from 0.2 to $8.9 \%$ for ${ }^{240} \mathrm{Pu} /{ }^{239} \mathrm{Pu}$.

All micro-sample clusters that are depicted in Fig. 3 showed within-sample homogeneity for their $\mathrm{Pu}$ isotopic composition. As micro-samples are not only representing single fuel particles but also fuel particle agglomerates, it can be considered that these isotopically homogeneous microsamples had probably been produced by fuel particles that originated from the same reactor fuel assemblies.

Heterogeneous Pu isotopic compositions In case of two micro-samples, significant within-sample heterogeneities were identified for their $\mathrm{Pu}$ isotopic composition (Fig. 5). Each micro-sample was analyzed by six subsequent static point ablations with a spot size of $100 \mu \mathrm{m}$. It is believed that these two micro-samples were created by two or more fuel particles, which originated from fuel assemblies with different burn-up grades, so that the isotopic compositions of these microsamples represent mixtures of several fuel particles with different burn-up grades.

The presence of varying $\mathrm{Pu}$ isotope ratios within individual micro-samples is also in good agreement with an investigation published by Boulyga and Prohaska [18], who observed

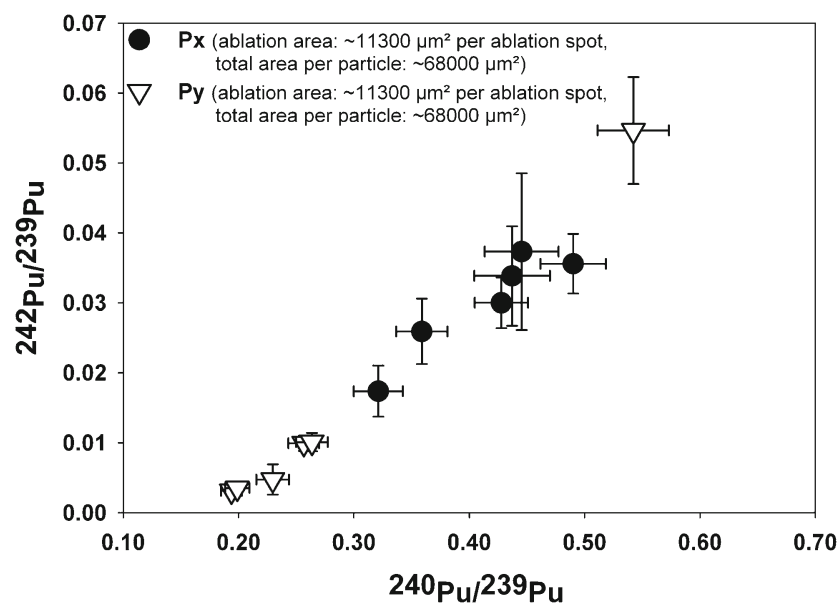

Fig. 5 Heterogeneous distribution of ${ }^{242} \mathrm{Pu} /{ }^{239} \mathrm{Pu}$ and ${ }^{240} \mathrm{Pu} /{ }^{239} \mathrm{Pu}$ isotope ratios measured in two Chernobyl micro-samples, Px and Py. Expanded $(k=2)$ measurement uncertainties $(U)$ are displayed the form of error bars

heterogeneities in the $\mathrm{U}$ isotopic signatures of micro-samples that were collected in the same batch as those analyzed in this study. They assumed an encapsulation of particles with different $U$ isotopic signatures in one micro-sample. It is still unclear if those particles got mixed during the explosion or during weathering and dissolution in soil. However, the presence of varying $\mathrm{Pu}$ or $\mathrm{U}$ isotopic signatures within one sample demonstrates the necessity of analytical methods that are capable of spatially resolving the inherent isotopic information.

Source attribution A sample's isotopic signature poses, like a human fingerprint, a distinct parameter, which can help to identify a sample's origin, providing that information, with which those isotopic signatures can be compared, is available in the literature or from other reports. In the case of Pu inputs into the environment due to nuclear weapon tests and nuclear accidents, much effort has been made in the past for establishing global $\mathrm{Pu}$ isotopic baselines [13], whereupon the Chernobyl fallout has been of particular interest. An overview about published $\mathrm{Pu}$ isotope ratios that were determined in both soil and single radioactive particles is given in Table 2 for comparison. The average ${ }^{242} \mathrm{Pu} /{ }^{239} \mathrm{Pu}$ and ${ }^{240} \mathrm{Pu} /{ }^{239} \mathrm{Pu}$ isotope ratios $\left(0.388(86)\right.$ and $0.028(11)$ for ${ }^{240} \mathrm{Pu} /{ }^{239} \mathrm{Pu}$ and ${ }^{242} \mathrm{Pu} /{ }^{239} \mathrm{Pu}$; calculated as average and $1 \times \mathrm{SD}$ ) that were calculated from the results of all micro-samples $(n=48)$ measured in this study are in good agreement with previously published results from bulk analyses of soil samples. Overall, the analyzed microsample entity $(n=48)$ showed a variation from low to high $\mathrm{Pu}$ isotope ratios, ranging from $0.007(2)$ to $0.047(8)$ for ${ }^{242} \mathrm{Pu} /{ }^{239} \mathrm{Pu}$ and from $0.183(13)$ to $0.577(40)$ for ${ }^{240} \mathrm{Pu} /{ }^{239} \mathrm{Pu}$. It should be noted that very limited data are provided in the literature regarding the $\mathrm{Pu}$ isotopic composition of individual particles collected in the vicinity of the accidental Chernobyl reactor $[36,37]$. Thus, no information about the $\mathrm{Pu}$ isotopic 
Table 2 Published $\mathrm{Pu}$ isotope ratios of the Chernobyl fallout and the reactor core

\begin{tabular}{lllll}
\hline Literature reference & ${ }^{240} \mathrm{Pu} /{ }^{239} \mathrm{Pu}$ & ${ }^{242} \mathrm{Pu} /{ }^{239} \mathrm{Pu}$ & Sample & Method \\
\hline Muramatsu et al. [45] & $0.403(9)^{\mathrm{a}}$ & n.a. & Soil $(n=8)$ & ICP-MS \\
Boulyga and Becker [43] & $0.396(14)^{\mathrm{a}}$ & n.a. & Soil $(n=8)$ & Soil $(n=1)$ \\
Nunnemann et al. [24] & $0.394(2)^{\mathrm{b}}$ & $0.027(1)^{\mathrm{b}}$ & Soil & RIMS \\
Erdmann et al. [25] & $0.378(2)^{\mathrm{a}, \mathrm{b}}$ & $0.024(1)^{\mathrm{a}, \mathrm{b}}$ & Hot particle $(n=1)$ & RIMS \\
Boulyga et al. [36] & $0.329(16)^{\mathrm{b}}$ & $0.021(3)^{\mathrm{b}}$ & Hot particle $(n=1)$ & RIMS \\
Wendt et al. [37] & $0.378(2)^{\mathrm{b}}$ & $0.088(1)^{\mathrm{b}}$ & Reactor core & RIMS \\
Kirchner and Noack [46] & $0.56^{\mathrm{a}, \mathrm{c}}$ & $0.044^{\mathrm{a}, \mathrm{c}}$ & Reactor core & Calculation \\
Begichev et al. [47] & $0.39^{\mathrm{a}, \mathrm{c}}$ & $0.045^{\mathrm{a}, \mathrm{c}}$ & Fuel particle clusters $(n=48)$ & Calculation \\
This study & $0.388(86)^{\mathrm{a}}$ & $0.028(11)^{\mathrm{a}}$ & Fuel particle clusters $(n=48)$ & LA-MC-ICP-MS \\
This study & $0.183(13)$ to $0.577(40)$ & $0.007(2)$ to $0.047(8)$ & &
\end{tabular}

${ }^{\text {a }}$ Average values

${ }^{\mathrm{b}}$ Isotope ratios were calculated from published isotopic compositions

${ }^{\mathrm{c}}$ Isotope ratios were calculated from published activity data

distribution has been available so far for the Chernobyl fallout. The present study reports for the first time variations of $\mathrm{Pu}$ isotope ratios in the Chernobyl fallout, which were not assessed previously due to the limited analyses of individual particles or micro-samples.

The observed variations can be explained by the fact that spent fuel was gradually replaced with freshly enriched uranium in the Chernobyl RBMK-1000 reactor during its operation. That resulted in different irradiation histories, and thus, in varying burn-up grades of the fuel assemblies over the reactor core at the time of the accident [47]. The differences in the burn-up over the reactor core were reflected in different ${ }^{242} \mathrm{Pu} /{ }^{239} \mathrm{Pu}$ and ${ }^{240} \mathrm{Pu} /{ }^{239} \mathrm{Pu}$ isotope ratios in the fuel assemblies. While ${ }^{239} \mathrm{Pu}$ is generated via neutron capture in ${ }^{238} \mathrm{U}$ and subsequent $\beta^{-}$decay, ${ }^{240} \mathrm{Pu},{ }^{241} \mathrm{Pu}$ and ${ }^{242} \mathrm{Pu}$ are generated via neutron capture $(n, \gamma)$ in ${ }^{239} \mathrm{Pu}$. Hence, higher fuel burn-up led to an increase of the heavier $\mathrm{Pu}$ isotope fraction and as a

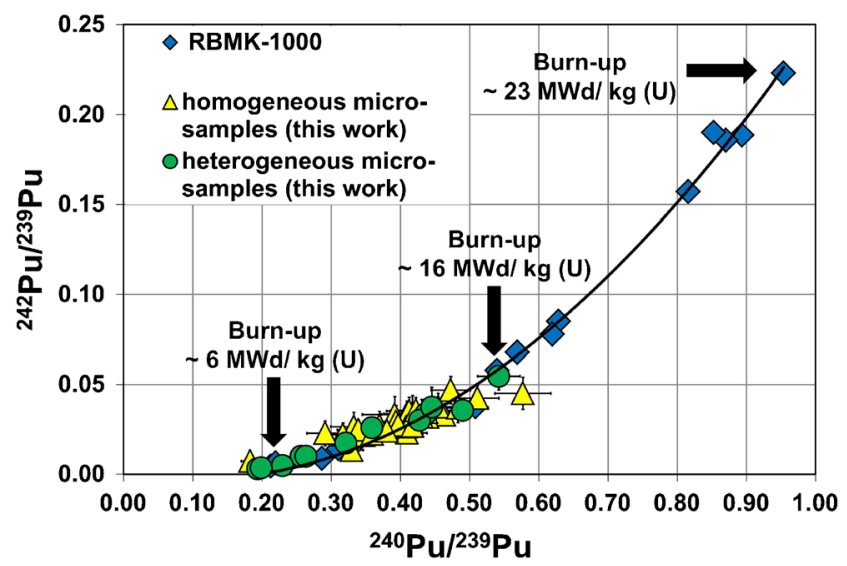

Fig. 6 Comparison of the Pu isotopic distribution measured in microsamples from the Chernobyl fallout with a typical $\mathrm{Pu}$ isotopic distribution of the RBMK-1000 reactor [48] having an initial ${ }^{235} \mathrm{U}$ enrichment of $\sim 2 \%$ consequence to higher ${ }^{242} \mathrm{Pu} /{ }^{239} \mathrm{Pu}$ and ${ }^{240} \mathrm{Pu} /{ }^{239} \mathrm{Pu}$ isotope ratios.

In Fig. 6, the measured Pu isotopic signatures are compared with the Pu isotopic composition distribution that is typical for a RBMK-1000 reactor type with an initial ${ }^{235} \mathrm{U}$ enrichment of about $2 \%$. The latter data, which were published by the Oak Ridge National Laboratory [48], can be taken for comparison in the first approximation as the RBMK-1000 Chernobyl reactor exhibited similar characteristics. The $\mathrm{Pu}$ isotopic distribution, which is plotted according to increasing burn-ups of the spent fuel of the RBMK-1000 reactor, follows a polynomial curve. As can be seen from Fig. 6, such a curve does also fit the distribution of the Pu isotopic signatures of all microsamples $(n=48)$ analyzed in this study, except for a few samples, which slightly deviate from the predicted distribution. It is believed that these deviations are either resulting from mixed isotope ratios as a result of insufficient spatial resolutions of both nuclear track radiography and laser ablation or from specific peculiarities of the nuclear core parameters of the Chernobyl reactor, which were not accounted for in the data from the Oak Ridge National Laboratory [48].

\section{Conclusions}

Overall, the fact that the determined $\mathrm{Pu}$ isotope ratios were in good agreement with the expected $\mathrm{Pu}$ isotopic composition over the Chernobyl reactor core demonstrates well that the combination of MC-ICP-MS and laser ablation represents a very powerful analytical method for determining accurate, spatially resolved actinide isotopic signatures in environmental samples. Its application for analyzing radioactive fuel particle clusters from the Chernobyl fallout allowed to gain new insights into the burn-up distribution of the reactor core at the time of the accident. Destruction-free particle pre-selection by 
means of nuclear track radiography has proven an important pre-requisite for saving valuable LA-MC-ICP-MS analysis time.

Moreover, this study demonstrates well that isotopic signatures can serve as strong indicators for linking material to their sources. However, it should be noted that the isotopic signature is only one indicator amongst many. Therefore, if available, more source attribution parameters (e.g. elemental impurities) should be taken into account for an unambiguous source attribution.

Acknowledgments This study has been carried out in the frame of S. Konegger-Kappel's $\mathrm{PhD}$ at the VIRIS Laboratory at the University of Natural Resources and Life Sciences, Vienna. Sergei Boulyga is highly acknowledged for developing the idea of this study and for the fruitful discussions of experimental approaches and analytical results. We are thankful for essential scientific inputs as well as for sharing his knowledge in mass spectrometry and actinide analysis.

The Austrian Science Fund FWF (START project 267-N11) and the International Atomic Energy Agency are highly acknowledged for financial support. The authors also thank Urs Klötzli from the Department of Lithospheric Research at the University of Vienna for providing the laser ablation system.

Open Access This article is distributed under the terms of the Creative Commons Attribution 4.0 International License (http:// creativecommons.org/licenses/by/4.0/), which permits unrestricted use, distribution, and reproduction in any medium, provided you give appropriate credit to the original author(s) and the source, provide a link to the Creative Commons license, and indicate if changes were made.

\section{References}

1. Taylor DM (1995) Environmental plutonium in humans. Appl Radiat Isot 46(11):1245-1252

2. Perelygin VP, Chuburkov YT (1997) Man-made plutonium in environment - possible serious hazard for living species. Radiat Measur 28(1-6):385-392

3. Salbu B (2009) Challenges in radioecology. J Environ Radioact 100(12):1086-1091

4. Mayer K, Wallenius M, Fanghänel T (2007) Nuclear forensic science-from cradle to maturity. J Alloys Compd 444-445:50-56

5. Donohue DL (2002) Peer reviewed: strengthened nuclear safeguards. Anal Chem 74 (1):28 A-35 A. doi: 10.1021/ac021909y

6. Zheng J, Tagami K, Watanabe Y, Uchida S, Aono T, Ishii N, Yoshida S, Kubota Y, Fuma S, Ihara S (2012) Isotopic evidence of plutonium release into the environment from the Fukushima DNPP accident. Scientific Rep 2

7. Schneider S, Walther C, Bister S, Schauer V, Christl M, Synal H-A, Shozugawa K, Steinhauser G (2013) Plutonium release from Fukushima Daiichi fosters the need for more detailed investigations. Scientific Rep 3

8. IAEA (2011) Radioactive particles in the environment: sources, particle characterization and analytical techniques. http://wwwpub.iaea.org/MTCD/publications/PDF/TE 1663 web.pdf. Accessed 21 June 2015. IAEA-TECDOC-1663

9. Salbu B, Lind OC (2005) Radioactive particles released from various nuclear sources. Radioprotection 40:27-32

10. Hu Q-H, Weng J-Q, Wang J-S (2010) Sources of anthropogenic radionuclides in the environment: a review. J Environ Radioact 101(6):426-437
11. Carter MW, Moghissi AA (1977) Three decades of nuclear testing. Health Phys 33(1):55-71

12. Ketterer ME, Szechenyi SC (2008) Determination of plutonium and other transuranic elements by inductively coupled plasma mass spectrometry: a historical perspective and new frontiers in the environmental sciences. Spectrochim Acta B At Spectrosc 63(7):719737

13. Kelley JM, Bond LA, Beasley TM (1999) Global distribution of Pu isotopes and ${ }^{237} \mathrm{~Np}$. Sci Total Environ 237-238:483-500

14. Kashparov VA, Lundin SM, Zvarych SI, Yoshchenko VI, Levchuk SE, Khomutinin YV, Maloshtan IM, Protsak VP (2003) Territory contamination with the radionuclides representing the fuel component of Chernobyl fallout. Sci Total Environ 317(1-3):105-119

15. Kashparov V, Yoschenko V, Levchuk S, Bugai D, Van Meir N, Simonucci C, Martin-Garin A (2011) Radionuclide migration in the experimental polygon of the red forest waste site in the Chernobyl zone. Part 1: characterization of the waste trench, fuel particle transformation processes in soils, biogenic fluxes and effects on biota. Appl Geochem 27(7):1348-1358

16. Kashparov VA, Protsak VP, Ahamdach N, Stammose D, Peres JM, Yoschenko VI, Zvarich SI (2000) Dissolution kinetics of particles of irradiated Chernobyl nuclear fuel: influence of $\mathrm{pH}$ and oxidation state on the release of radionuclides in the contaminated soil of Chernobyl. J Nucl Mater 279(2-3):225-233

17. Salbu B, Krekling T, Lind OC, Oughton DH, Drakopoulos M, Simionovici A, Snigireva I, Snigirev A, Weitkamp T, Adams F, Janssens K, Kashparov VA (2001) High energy X-ray microscopy for characterisation of fuel particles. Nucl Instrum Meth A 467468(Part 2 (0)):1249-1252

18. Boulyga SF, Prohaska T (2008) Determining the isotopic compositions of uranium and fission products in radioactive environmental microsamples using laser ablation ICP-MS with multiple ion counters. Anal Bioanal Chem 390(2):531-539

19. Hrnecek E, Steier P, Wallner A (2005) Determination of plutonium in environmental samples by AMS and alpha spectrometry. Appl Radiat Isot 63(5-6):633-638

20. Vajda N, Kim C-K (2010) Determination of Pu isotopes by alpha spectrometry: a review of analytical methodology. J Radioanal Nucl Chem 283(1):203-223

21. Chamizo E, Jiménez-Ramos MC, Enamorado SM, García-León M, García-Tenorio R, Mas JL, Masqué P, Merino J, Sanchez-Cabeza JA (2010) Characterisation of the plutonium isotopic composition of a sediment core from Palomares, Spain, by low-energy AMS and alpha-spectrometry. Nucl Instrum Meth B 268:1273-1276

22. Kim C-S, Kim C-K, Martin P, Sansone U (2007) Determination of $\mathrm{Pu}$ isotope concentrations and isotope ratio by inductively coupled plasma mass spectrometry: a review of analytical methodology. J Anal At Spectrom 22(7):827-841

23. Jakopic R, Richter S, Kühn H, Aregbe Y (2010) Determination of ${ }^{240} \mathrm{Pu} /{ }^{239} \mathrm{Pu},{ }^{241} \mathrm{Pu} /{ }^{239} \mathrm{Pu}$ and ${ }^{242} \mathrm{Pu} /{ }^{239} \mathrm{Pu}$ isotope ratios in environmental reference materials and samples from Chernobyl by thermal ionization mass spectrometry (TIMS) and filament carburization. J Anal At Spectrom 25(6):815-821

24. Nunnemann M, Erdmann N, Hasse HU, Huber G, Kratz JV, Kunz P, Mansel A, Passler G, Stetzer O, Trautmann N, Waldek A (1998) Trace analysis of plutonium in environmental samples by resonance ionization mass spectroscopy (RIMS). J Alloys Compd 271-273: 45-48

25. Erdmann N, Herrmann G, Huber G, Köhler S, Kratz JV, Mansel A, Nunnemann M, Passler G, Trautmann N, Turchin A, Waldek A (1997) Resonance ionization mass spectroscopy for trace determination of plutonium in environmental samples. Fresenius $\mathrm{J}$ Anal Chem 359(4):378-381

26. Becker JS (2003) Mass spectrometry of long-lived radionuclides. Spectrochim Acta B 58(10):1757-1784 
27. Boulyga SF (2011) Mass spectrometric analysis of long-lived radionuclides in bio-assays. Int J Mass Spectrom 307(1-3):200-210

28. Hou X, Roos P (2008) Critical comparison of radiometric and mass spectrometric methods for the determination of radionuclides in environmental, biological and nuclear waste samples. Anal Chim Acta 608(2):105-139

29. Lariviere D, Taylor VF, Evans RD, Cornett RJ (2006) Radionuclide determination in environmental samples by inductively coupled plasma mass spectrometry. Spectrochim Acta B 61(8):877-904

30. Becker JS (2005) Inductively coupled plasma mass spectrometry (ICP-MS) and laser ablation ICP-MS for isotope analysis of long-lived radionuclides. Int $\mathrm{J}$ Mass Spectrom 242(2-3):183-195

31. Pointurier F, Pottin A-C, Hubert A (2011) Application of nanosecond-UV laser ablation-inductively coupled plasma mass spectrometry for the isotopic analysis of single submicrometersize uranium particles. Anal Chem 83(20):7841-7848

32. Aregbe Y, Prohaska T, Stefanka Z, Széles É, Hubert A, Boulyga S (2011) Report on the workshop on direct analysis of solid samples using laser ablation-inductively coupled plasma-mass spectrometry (LA-ICP-MS) - organised by the ESARDA working group on standards and techniques for destructive analysis (WG DA). ESARDA Bull 46:136-145

33. Kappel S, Boulyga S, Dorta L, Günther D, Hattendorf B, Koffler D, Laaha G, Leisch F, Prohaska T (2013) Evaluation strategies for isotope ratio measurements of single particles by LA-MC-ICPMS. Anal Bioanal Chem 405(9):2943-2955

34. Taylor RN, Warneke T, Milton JA, Croudace IW, Warwick PE, Nesbitt RW (2001) Plutonium isotope ratio analysis at femtogram to nanogram levels by multicollector ICP-MS. J Anal At Spectrom 16(3):279-284

35. Esaka F, Suzuki D, Magara M (2015) Identifying uranium particles using fission tracks and microsampling individual particles for analysis using thermal ionization mass spectrometry. Anal Chem 87(5): 3107-3113

36. Boulyga SF, Erdmann N, Funk H, Kievets MK, Lomonosova EM, Mansel A, Trautmann N, Yaroshevich OI, Zhuk IV (1997) Determination of isotopic composition of plutonium in hot particles of the Chernobyl area. Radiat Measur 28(1-6):349-352

37. Wendt K, Blaum K, Bushaw BA, Grüning C, Horn R, Huber G, Kratz JV, Kunz P, Müller P, Nörtershäuser W, Nunnemann M,
Passler G, Schmitt A, Trautmann N, Waldek A (1999) Recent developments in and applications of resonance ionization mass spectrometry. Fresenius J Anal Chem 364(5):471-477

38. Kappel S, Boulyga SF, Prohaska T (2012) Direct uranium isotope ratio analysis of single micrometer-sized glass particles. J Environ Radioact 113:8-15

39. Fietzke J, Liebetrau V, Günther D, Gurs K, Hametner K, Zumholz K, Hansteen TH, Eisenhauer A (2008) An alternative data acquisition and evaluation strategy for improved isotope ratio precision using LA-MC-ICP-MS applied to stable and radiogenic strontium isotopes in carbonates. J Anal At Spectrom 23(7):955-961

40. JCGM 100:2008. GUM 1995 with minor corrections. Evaluation of measurement data - guide to the expression of uncertainty in measurement

41. Ellison SLR, Williams A (Eds). Eurachem/CITAC guide: quantifying uncertainty in analytical measurement, 3rd (edn), (2012) ISBN 978-0-948926-30-3. Available from www.eurachem.org

42. Boulyga SF, Tibi M, Heumann KG (2004) Application of isotopedilution laser ablation ICP-MS for direct determination of $\mathrm{Pu}$ concentrations in soils at $\mathrm{pg} \mathrm{g}^{-1}$ levels. Anal Bioanal Chem 378(2): 342-347

43. Boulyga SF, Becker JS (2002) Isotopic analysis of uranium and plutonium using ICP-MS and estimation of burn-up of spent uranium in contaminated environmental samples. J Anal At Spectrom 17(9):1143-1147

44. Boulyga SF, Desideri D, Meli MA, Testa C, Becker JS (2003) Plutonium and americium determination in mosses by laser ablation ICP-MS combined with isotope dilution technique. Int J Mass Spectrom 226(3):329-339

45. Muramatsu Y, Rühm W, Yoshida S, Tagami K, Uchida S, Wirth E (2000) Concentrations of ${ }^{239} \mathrm{Pu}$ and ${ }^{240} \mathrm{Pu}$ and their isotopic ratios determined by ICP-MS in soils collected from the Chernobyl 30km zone. Environ Sci Technol 34(14):2913-2917

46. Kirchner G, Noack CC (1988) Core history and nuclide inventory of the Chernobyl core at the time of the accident. Nucl Saf 29(1):1-3

47. Begichev SN, Borovoj AA, Burlakov EB, Gagarinsky AJ, Demin VF, Khrulev AA, Khodakovsky IL (1990) In: Rogers JT (ed) Fission product transport processes in reactor accidents. Hemisphere, New York, pp 717-734

48. ORIGEN-ARP Cross-section libraries for the RBMK-1000 system. http://www.ornl.gov/sci/scale/Publications/Murphy/ORNL_TM_ 2006 139.pdf. Accessed 7 Mar 2012. (2006) 